Discussion Paper No. 05-56

\title{
Economic Development and $\mathrm{CO}_{2}$ Emissions:
}

\section{A Nonparametric Panel Approach}

Théophile Azomahou, François Laisney and Phu Nguyen Van

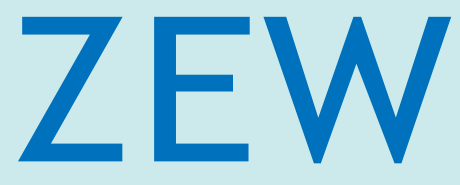

Zentrum für Europäische Wirtschaftsforschung $\mathrm{GmbH}$

Centre for European

Economic Research 
Discussion Paper No. 05-56

\title{
Economic Development and $\mathrm{CO}_{2}$ Emissions:
}

\section{A Nonparametric Panel Approach}

\author{
Théophile Azomahou, François Laisney \\ and Phu Nguyen Van
}

Download this ZEW Discussion Paper from our ftp server:

\section{ftp://ftp.zew.de/pub/zew-docs/dp/dp0556.pdf}

Die Discussion Papers dienen einer möglichst schnellen Verbreitung von neueren Forschungsarbeiten des ZEW. Die Beiträge liegen in alleiniger Verantwortung der Autoren und stellen nicht notwendigerweise die Meinung des ZEW dar.

Discussion Papers are intended to make results of ZEW research promptly available to other economists in order to encourage discussion and suggestions for revisions. The authors are solely responsible for the contents which do not necessarily represent the opinion of the ZEW. 


\section{Non technical summary}

The relationship between economic development and environmental quality has been extensively explored in recent years. The shape of this relationship has implications for the definition of an appropriate joint economic and environmental policy. In the literature, this animated debate revolves around the existence of an Environmental Kuznets Curve, which implies that, starting from low levels of income per capita, environmental degradation increases, but after a certain level of income (turning point) it diminishes.

This study investigates the question of the existence of an EKC using a nonparametric approach. In this framework, no a priori parametric functional form is assumed for modelling the relationship between carbon dioxide $\left(\mathrm{CO}_{2}\right)$ emissions and GDP per capita. The main reason for studying $\mathrm{CO}_{2}$ emissions is that they play a focal role in the current debate on environmental protection and sustainable development. $\mathrm{CO}_{2}$ has been recognized by most scientists as a major source of global warming through its greenhouse effects. Another reason is that $\mathrm{CO}_{2}$ emissions are directly related to the use of energy, which is an essential factor in the world economy, both for production and consumption. Therefore, the relationship between $\mathrm{CO}_{2}$ emissions and economic growth has important implications for environmental and economic policies.

To estimate this relationship, we use information drawn from several data sets. $\mathrm{CO}_{2}$ emissions measured in metric tons are obtained from the data base of the Carbon Dioxide Information Analysis Center, Oak Ridge National Laboratory. Real GDP per capita series, measured in thousand constant dollars at 1985 prices, are drawn from the Penn World Table 5.6. The resulting data set, a balanced panel of 100 countries, covers the period 1960-1996.

We first consider the issue of structural stability of the relationship between $\mathrm{CO}_{2}$ emissions and GDP per capita, and we find evidence of structural stability of the relationship over the period 1960-1996. Based on this result, the panel nature of the data allows us to specify a nonparametric model that accounts for heterogeneity across countries. We find that the relationship between $\mathrm{CO}_{2}$ emissions and GDP per capita is upward sloping, and that the usually adopted polynomial functional form which leads to the environmental Kuznets curve in several studies is rejected against our nonparametric model. Moreover, by comparing different estimation methods for the parametric model, we are able to relate the finding of an EKC to the erroneous assumption of strict exogeneity of GDP per capita.

As regards policy concerns, our results imply that economic development is not a sufficient condition to reduce $\mathrm{CO}_{2}$ emissions. Thus all countries should make an effort to reduce these emissions in order to reduce global warming. 


\title{
Economic development and $\mathrm{CO}_{2}$ emissions: a nonparametric panel approach*
}

\author{
Théophile Azomahou ${ }^{a}$, François Laisney ${ }^{a, b \dagger}$, Phu Nguyen $\operatorname{Van}^{c}$ \\ ${ }^{a}$ BETA-Theme, Université Louis Pasteur, Strasbourg 1 \\ ${ }^{b}$ ZEW, Center for European Economic Research, Mannheim \\ ${ }^{c}$ THEMA, CNRS, Cergy-Pontoise
}

July 2005

\begin{abstract}
We examine the empirical relation between $\mathrm{CO}_{2}$ emissions per capita and GDP per capita during the period 1960-1996, using a panel of 100 countries. Relying on the nonparametric poolability test of Baltagi et al. (1996), we find evidence of structural stability of the relationship. We then specify a nonparametric panel data model with country-specific effects. Estimation results show that this relationship is upward sloping. Nonparametric specification tests do not reject monotonicity but do reject the polynomial functional form which leads to the environmental Kuznets curve in several studies.
\end{abstract}

Key words: Environmental Kuznets curve; panel data, poolability test, monotonicity test, specification test JEL classification: C14; C23; O10; O40

${ }^{*}$ We thank the Carbon Dioxide Information Analysis Center, Oak Ridge National Laboratory, for providing $\mathrm{CO}_{2}$ emissions data. Parts of this paper were written while Théophile Azomahou was visiting CORE, Belgium, in 2000. We are also indebted to Alain Ayong Le Kama, Luc Bauwens, Stefan Boeters, Marc Germain, Qi Li, Bettina Müller, Pierre Pestieau, Marc Willinger, and participants in the 50th congress of the French Economic Association, Paris, September 2001, and in the 11th annual EAERE conference, Southampton, June 2001. The helpful comments of four anonymous referees and a co-editor of this journal are gratefully acknowledged. All remaining errors are our own.

${ }^{\dagger}$ Corresponding author: BETA, Université Louis Pasteur, 61, avenue de la Forêt Noire, 67085 Strasbourg Cedex, France; Tel: +33 390242 080; Fax: +33 390242 071; E-mail: fla@cournot.u-strasbg.fr 


\section{Introduction}

The relationship between economic development and environmental quality has been extensively explored in recent years. The shape of this relationship has implications for the definition of an appropriate joint economic and environmental policy: depending on whether there is a negative or a positive influence of economic development on environmental quality, policy recommendations will differ. In the literature, this animated debate revolves around the existence of an Environmental Kuznets Curve (or inverted-U shaped curve, EKC), which implies that, starting from low levels of income per capita, environmental degradation increases, but after a certain level of income (turning point) it diminishes. Despite some exceptions, empirical studies are generally based on ad hoc parametric specifications with little attention paid to model robustness; yet different parametric specifications can lead to significantly different conclusions, and a functional misspecification problem is likely to occur. Popular parametric functional forms are linear, quadratic, and cubic polynomials in GDP per capita.

This study investigates the question of the existence of an EKC using a nonparametric approach. In this framework, no a priori parametric functional form is assumed for modelling the relationship between carbon dioxide $\left(\mathrm{CO}_{2}\right)$ emissions and GDP per capita. While there exist many panel studies on the existence of an EKC for $\mathrm{CO}_{2}$, with various conclusions as we will see in detail in the next section, we offer the first nonparametric panel study on that topic that is able to point out an important source of these divergencies. ${ }^{1}$

We follow the bulk of the literature on this relationship by not controlling for possible determinants for $\mathrm{CO}_{2}$ emissions, like technological change, energy prices, etc. Of course, it is not our intention to deny the role of these factors. However, a number of points can be made in support of our choice. The first, obvious one, concerns data limitations. In this respect, it is important to note that using panel methods that sweep country effects away lets us control implicitly for any time invariant determinant. The second obvious point concerns comparability with existing studies. A more technical point concerns the curse of dimensionality in nonparametric studies: adding discrete regressors to a nonparametric regression does not alter the speed of convergence of the estimator, but adding continuous regressors does - although

\footnotetext{
${ }^{1}$ The only other nonparametric panel study available, as far as we know, is the study of Bertinelli and Strobl (2005), but their paper is much more modest in scope - although it addresses broadly the same issue, and reaches a qualitatively similar conclusion of absence of an EKC. Moreover the first version of this paper dates back to 2001 .
} 
admittedly additional regressors could be included in a parametric way (as illustrated by Bertinelli and Strobl, 2005, although they include only country and year effects as supplementary regressors). More importantly, we are not concerned here with obtaining best predictions for $\mathrm{CO}_{2}$ emissions next year, say, but with the shape of the relationship with GDP. In this respect, determinants of $\mathrm{CO}_{2}$ emissions which are not correlated with GDP become irrelevant. Moreover the impact of determinants which are correlated with GDP will be captured in the effect of GDP. Depending on the question asked, this can be seen as a drawback or as an advantage. It is a drawback if we purport to determine the ceteris paribus impact of GDP on $\mathrm{CO}_{2}$ emissions - but what list of regressors would guarantee this? It is an advantage if we are interested in the global effect of GDP, including indirect effects linked with omitted variables. This is indeed the stance we take here. While the results of our study will not enable us to make precise policy prescriptions, we will be in a position to intervene convincingly in the long debate on the existence of EKCs. Finding an increasing profile would default the hope for sustained economic growth without excessive increase in $\mathrm{CO}_{2}$ emissions in the absence of active policies designed to modify the shape of the relationship revealed on the basis of the current and past policies.

The main reason for studying $\mathrm{CO}_{2}$ emissions is that they play a focal role in the current debate on environment protection and sustainable development. $\mathrm{CO}_{2}$ has been recognized by most scientists as a major source of global warming through its greenhouse effects. Pollutants like sulphur oxides or oxides of nitrogen, have a more local impact on the environment. Another reason is that $\mathrm{CO}_{2}$ emissions are directly related to the use of energy, which is an essential factor in the world economy, both for production and consumption. Therefore, the relationship between $\mathrm{CO}_{2}$ emissions and economic growth has important implications for environmental and economic policies.

To estimate this relationship, we use information drawn from several data sets. $\mathrm{CO}_{2}$ emissions measured in metric tons are obtained from the data base of the Carbon Dioxide Information Analysis Center, Oak Ridge National Laboratory (see Marland et al., 1999). Real GDP per capita series, measured in thousand constant dollars at 1985 prices, are drawn from the Penn World Table 5.6 (Summers and Heston, 1991). The resulting data set, a balanced panel of 100 countries (listed in Table A), covers the period 1960-1996.

We first consider the issue of structural stability of the relationship between $\mathrm{CO}_{2}$ emissions and GDP per capita. The question is whether it is suitable to assume 
the constancy of parameters or functions over time. For this purpose, we use the poolability test of Baltagi et al. (1996) and find evidence of structural stability of the relationship over the period 1960-1996. Based on this result, we specify a nonparametric panel data model with country-specific effects. The model is estimated using local kernel regression and marginal integration along the lines of Linton and Nielsen (1995). We also perform the functional monotonicity test of Bowman et al. (1998) and the specification test of Li and Wang (1998), in order to compare our nonparametric estimates with parametric analogues. We find that the relationship between $\mathrm{CO}_{2}$ emissions and GDP per capita is upward sloping, and that the usually adopted polynomial functional form which leads to the environmental Kuznets curve in several studies is rejected against our nonparametric model. Moreover, we are able to relate the finding of an EKC to the erroneous assumption of strict exogeneity of GDP per capita.

The paper is organised as follows. In Section 2, we present a review of the literature on EKCs, focusing mainly on issues related to econometric specifications. Section 3 presents the nonparametric framework retained. Data description and estimation results are covered in Sections 4 and 5, respectively. Section 6 concludes the study.

\section{Literature overview on the EKC}

In this section, we discuss empirical studies on the $\mathrm{EKC}$, focusing on issues related to functional forms in econometric specifications. The list of references cited below is by no means exhaustive. ${ }^{2}$

Although evidence of an EKC has been found for several environmental indicators, these findings are not unanimously accepted in the literature. The case of $\mathrm{CO}_{2}$ emissions is a good example. An EKC was found in the studies of Roberts and Grimes (1997), Schmalensee et al. (1998), and Sun (1999), among others, in contradiction with the results obtained by, e.g., Shafik (1994), Holtz-Eakin and Selden (1995), Heil and Selden (2001), and Taskin and Zaim (2000).

Most of these empirical studies have relied on parametric specifications. For example, Holtz-Eakin and Selden (1995) investigated the reduced-form relationship between national $\mathrm{CO}_{2}$ emissions per capita and real GDP per capita for a sample of

\footnotetext{
${ }^{2}$ For more detailed discussions, see the special issues of Environment and Development Economics (1997), and Ecological Economics (1998). See also the surveys of Stern (1998, 2004), Panayotou (2000a,b), Levinson (2002) and Dasgupta et al. (2002).
} 
130 countries over the period 1951-1986. They used a quadratic polynomial model with fixed country- and year-specific effects, and found an out-of-sample EKC, with an out-of-sample turning point equal to $\$ 35,428$ per capita (in 1986 US dollars). ${ }^{3}$ Grossman and Krueger $(1993,1995)$ studied the effect of GDP per capita on various local environmental indicators, using a random city-specific effect model. They found no evidence that environmental quality deteriorates with economic development. For most indicators - sulfur dioxide $\left(\mathrm{SO}_{2}\right)$ concentrations, suspended particulate matter (SPM), biological oxygen demand, chemical oxygen demand, and arsenic in rivers - an inverted-U shape curve emerged. In particular, the turning point estimates for these pollutants were under $\$ 8,000$ (in 1985 US dollars) of GDP per capita. Selden and Song (1994) investigated this relationship for four air pollutants - SPM, $\mathrm{SO}_{2}$, oxides of nitrogen $\left(\mathrm{NO}_{x}\right)$, and carbon monoxide $(\mathrm{CO})$ - with data coming from the same sources as Grossman and Krueger (1993, 1995), and found evidence of an EKC for all four pollutants, but the turning points for SPM and $\mathrm{SO}_{2}$ largely exceeded $\$ 8,000$. Shafik (1994) examined the relationship between various environmental quality indicators and income per capita for the period 1960-1990, and obtained several results, among which a clear evidence of EKCs for deforestation, $\mathrm{SPM}$, and $\mathrm{SO}_{2}$, but an upward sloping relationship for $\mathrm{CO}_{2}$. Shafik (1994) used all three polynomial functions (linear, squared, and cubic) with fixed individual effects (city or country, depending on the data), but did not provide specification tests in choosing the appropriate model.

Kaufmann et al. (1998) used fixed and random effect panel models with a second order polynomial for 23 countries between 1974 and 1989, and obtained an inverted U-shape relation (i.e. an EKC) between atmospheric concentration of $\mathrm{SO}_{2}$ and the spatial intensity of economic activity, measured either by the ratio between GDP and the country's area or the product between GDP per capita and population density. However, they also found evidence for a U-shape relationship (not an EKC) between $\mathrm{SO}_{2}$ concentration and GDP per capita. Taking trade into account, Suri and Chapman (1998) investigated data on 33 countries for the period 1971-1991, using a panel fixed effect model and a second order polynomial, and found evidence of an EKC for consumption per capita of primary commercial energy, expressed in terms of oil equivalents. Hettige et al. (2000) performed various econometric estimations with a parametric functional form on a new panel data set constructed from direct

\footnotetext{
${ }^{3}$ In fact, strictly speaking, one should speak here of an increasing profile rather than of an EKC, but this is the interpretation the authors themselves give of ther results, since they perform out of sample predictions.
} 
observations of industrial water pollution, measured by biological oxygen demand at the plant level, for 12 countries over the period 1989-1995. Their results reject the EKC hypothesis and show that industrial water pollution rises rapidly for middle income and remains unchanged thereafter. Heil and Selden (2001) used a second order polynomial in income per capita with several specification tests to study a panel data from 135 countries over the period 1951-1992. They found a monotonous increasing relationship between $\mathrm{CO}_{2}$ emissions and income per capita in both the levels model and the logarithmic model (an out-of-sample EKC was found in the levels model).

Schmalensee et al. (1998) adopted a more flexible model to evaluate the effect of income on carbon emissions and also found evidence of an EKC for a sample of 141 countries over the period 1950-1990. The specification consisted in a piecewise linear function with fixed year- and country-specific effects. Koop and Tole (1999) suggested a model with random coefficients that differ across but not within countries over time, and found little evidence for the existence of an EKC for deforestation. Using parametric specifications, Dijkgraaf and Vollebergh (2005), and List and Gallet (1999), underlined the heterogeneity across units using panel data on national $\mathrm{CO}_{2}$ emissions for the period 1960-1997, and panel data on US state-level $\mathrm{SO}_{2}$ and $\mathrm{NO}_{x}$ emissions for the period 1929-1994, respectively. Stern and Common (2001) found the relationship between national $\mathrm{SO}_{2}$ emissions and income from 1850 to 1990 to be sensitive to econometric specifications and data sampling: they obtain a monotonous increasing curve for the whole sample but an EKC for a sample of high-income countries; a monotonous increasing curve arises for both the high-income sample and for the complete sample when estimation in first differences is performed. ${ }^{4}$ Using the complete panel data on ambient air pollution, Harbaugh et al. (2002) showed that the relationship between national income and pollution is highly sensitive to the choice of functional form, covariates, and to the choice data sampling. Thus, despite these flexible specifications, the criticism addressed to the ad hoc parametric functional forms still applies. Aslanidis and Xepapadeas (2004) use a smooth transition model, and thus an even more flexible parametric specification, to study US state-level $\mathrm{SO}_{2}$ and NO emissions over the period 1929-1994 and find an $\mathrm{N}$ shape for $\mathrm{SO}_{2}$ emissions, while the profile for NO emissions is first increasing and then flattens out. They use a fixed-effects-type estimator, to which we come back in Section 5.2.

Recently, some authors resorted to semi- and nonparametric techniques, which

\footnotetext{
${ }^{4}$ This is an important point, to which we shall come back in our own empirical work (Sub-section $5.2)$.
} 
do not require the specification of a functional form, in order to investigate the existence of EKCs. Taskin and Zaim (2000) used a nonparametric approach to study the environmental efficiency. On the basis of cross-sectional data for $\mathrm{CO}_{2}$ emissions, they computed environmental efficiency indices for low- and high income countries between 1975 and 1990. The relationship between the environmental efficiency index and GDP per capita displayed a U shape followed by an inverted U, i.e. the EKC hypothesis holds only for countries with sufficiently high GDP per capita (more than \$5000). Millimet and Stengos (2000), and Millimet et al. (2003), used semiparametric partially linear models for US data, and obtained EKCs for $\mathrm{SO}_{2}$ and $\mathrm{NO}_{x}$, and $\mathrm{N}$-shaped curves for some other pollutants (stack air releases, water releases, underground injections, and total pollutants emissions). Roy and van Kooten (2004) use a similar model for US data for the year 1990, and find U shapes (not inverted) for CO and $\mathrm{NO}_{x}$. Bertinelli and Strobl (2005) also use a partially linear model for a panel of countries for 1950-1990, again using a fixed-effects-type estimator, and for $\mathrm{SO}_{2}$ and $\mathrm{CO}_{2}$ they find a positive relationship at low incomes which flattens out before increasing again for high incomes.

\section{$3 \quad$ Nonparametric analysis}

This section states the methodological background of the study. We use a nonparametric specification to investigate the relationship between $\mathrm{CO}_{2}$ emissions per capita and real GDP per capita. This specification enables us to estimate the shape of the relationship, avoiding any ad hoc choice of a parametric functional form, e.g. linear, quadratic or cubic functions. The model accounts for heterogeneity in a limited way by incorporating country-specific effects and by allowing a priori the effect of GDP per capita on $\mathrm{CO}_{2}$ emissions to vary with time. Our main concern is the specification issue related to the functional form and its stability over time, rather than the heterogeneity issue discussed in Koop and Tole (1999), Dijkgraaf et al. (2005), and List and Gallet (1999).

\subsection{Model}

Let us consider the following nonparametric panel model with individual effects for the relationship between $\mathrm{CO}_{2}$ emissions of country $i$ in period $t, y_{i t}$, and the country's per capita GDP in the same period, $x_{i t}$ :

$$
y_{i t}=G_{t}\left(x_{i t}\right)+\varepsilon_{i t}, \quad i=1, \ldots, N, \quad t=1, \ldots, T,
$$


with $\varepsilon_{i t}=\mu_{i}+\nu_{i t}$. Under the null hypothesis of poolability, to which we shall come back, $G_{t}$ does not vary with $t$ and thus $G_{t}=G$ for all $t$. Let us denote by $\mathbf{v}_{i}^{t}$ the vector of idiosyncratic error terms pertaining to unit $i$ up to period $t: \mathbf{v}_{i}^{t}=\left(\nu_{i 1}, \ldots, \nu_{i t}\right)^{\prime}$. We assume that the vectors $\mathbf{v}_{1}^{T}, \ldots, \mathbf{v}_{N}^{T}$ are independent and identically distributed, but unless otherwise stated no restriction is placed on the temporal variance structure of each vector $\mathbf{v}_{i}^{T}$. We may want to assume predeterminedness of $x_{i t}$ for this model, in the sense of conditional mean independence of $\nu_{i t}$ from $x_{i t}$ given $\mathbf{x}_{i}^{t-1}$ :

$$
E\left[\nu_{i t} \mid x_{i t}, \mathbf{x}_{i}^{t-1}\right]=E\left[\nu_{i t} \mid x_{i t}, x_{i, t-1}, \ldots, x_{i 1}\right]=E\left(\nu_{i t} \mid \mathbf{x}_{i}^{t}\right)=0,
$$

but we remain agnostic about the joint distribution of the individual effect $\mu_{i}$ and $\mathbf{x}_{i}^{T}$. Thus we make no assumption on $E\left[\mu_{i} \mid x_{i s_{1}}, \ldots, x_{i s_{K}}\right]$ for any set of dates $s_{1}, \ldots, s_{K}$ in $\{1, \ldots, T\} .{ }^{5}$

In order to eliminate the country-specific effect $\mu_{i}$ we take first differences in equation (1), which gives

$$
y_{i t}-y_{i t-1}=G_{t}\left(x_{i t}\right)-G_{t-1}\left(x_{i t-1}\right)+\nu_{i t}-\nu_{i t-1} .
$$

The following central assumption, which we shall call the first difference assumption,

$$
E\left[\nu_{i t}-\nu_{i t-1} \mid x_{i t}, x_{i t-1}\right]=0, \quad i=1, \ldots, N, \quad t=2, \ldots, T,
$$

identifies the functions $\Psi_{t}$ defined as:

$$
\Psi_{t}\left(\mathbf{x}_{i t}\right):=E\left[y_{i t}-y_{i t-1} \mid x_{i t}, x_{i t-1}\right]=G_{t}\left(x_{i t}\right)-G_{t-1}\left(x_{i t-1}\right),
$$

with $\mathbf{x}_{i t}=\left(x_{i t}, x_{i t-1}\right)^{\prime}$. For later reference, a discussion of (4) will be useful, but the reader may choose to skip it first. ${ }^{6}$

A special case under which (4) is satisfied is strict exogeneity, defined here as ${ }^{7}$

$$
E\left[\nu_{i t} \mid \mathbf{x}_{i}^{T}\right]=E\left[\nu_{i t} \mid x_{i 1}, \ldots, x_{i T}\right]=0, \quad i=1, \ldots, N, \quad t=1, \ldots, T,
$$

since then $E\left[y_{i t}-y_{i t-1} \mid x_{i 1}, \ldots, x_{i T}\right]=G_{t}\left(x_{i t}\right)-G_{t-1}\left(x_{i t-1}\right)=\Psi_{t}\left(\mathbf{x}_{i t}\right)$, and applying the theorem of successive projections to the latter gives relation (5). Strict exogeneity is needed for within estimation of parametric panel models similar to in our situation, strict exogeneity precludes any feedback from the current value of $\mathrm{CO}_{2}$ emissions on future values of GDP, which is not a realistic assumption.

\footnotetext{
${ }^{5}$ See Arellano and Honoré (2001), Section 3.2.

${ }^{6}$ Given that $T=37$ in our empirical work, we do not discuss the very special case where $T=2$.

${ }^{7}$ In this framework where we focus on elimination of the individual effect, conditioning on the latter (see e.g. Wooldridge, 2002) does not seem useful. See also Arellano and Honoré (2001).
} 
It is also revealing to note that predeterminedness is neither necessary nor sufficient for (4). It is not sufficient, because under predeterminedness alone

$$
E\left[\nu_{i t}-\nu_{i t-1} \mid \mathbf{x}_{i}^{t}\right]=-E\left[\nu_{i t-1} \mid \mathbf{x}_{i}^{t}\right]
$$

which will not be zero in general. Thus the extension of predeterminedness yielding (5) is

$$
E\left[\nu_{i t} \mid \mathbf{x}_{i}^{t+1}\right]=E\left[\nu_{i t} \mid \mathbf{x}_{i}^{t}, x_{i t+1}\right]=0, \quad i=1, \ldots, N, \quad t=1, \ldots, T-1,
$$

with (2) still holding for $t=T$. In our situation, this only precludes feedback from the current value of $\mathrm{CO}_{2}$ emissions on next year's value of GDP, but not on later values, which appears much less stringent than strict exogeneity. However, (2) is not a necessary condition for the first difference assumption, since if $\nu_{i t}$ is a random walk (4) is satisfied without further assumption on $E\left[\nu_{i t} \mid \mathbf{x}_{i}^{t}\right]$. This closes our discussion of assumption (4), which we maintain in the sequel.

If there is enough variation in $x_{i t}$ and $x_{i t-1}$ over the index $i$ and between $t-1$ and $t$, then function $\Psi_{t}$ is identified, and $G_{t}$ and $G_{t-1}$ will be identified up to a common constant. Thus, even in the nonpooled nonparametric model, the country-specific effects can be eliminated up to an additive constant.

We now turn to a test for data poolability, the question being whether it is suitable to assume the constancy of the relationship over time. The main reason why we are interested in the poolability test in the time dimension is that we are looking for some structural change in the relationship. Nonrejection of this assumption does not imply that countries represented in the sample have the same pattern of reaction to economic growth in their emission behaviour. Indeed browsing over the 100 scatter plots of $\mathrm{CO}_{2}$ emissions against GDP reveals that there are six types of profile (the numbers in brackets give the number of countries of this type): flat (48), increasing (25), increasing then flat (14), inverted U (5), elongated N shape (5), decreasing (3). Appendix A lists the countries together with their type. While the last three types concern the upper range of the (per capita) GDP distribution, and the first the lower range, types 2 and 3 are spread across the whole distribution. Testing for poolability in the cross-country dimension would certainly reject, but it would be beside the point, since what we are looking for is a relationship at all levels of GDP.

Baltagi et al. (1996) proposed a nonparametric poolability test which has the advantage of being robust to functional form misspecification. The null is $\mathrm{H}_{0}: G_{t}=$ $G_{s}$ for all $t$ and $s$ almost everywhere, and the alternative is $\mathrm{H}_{1}: G_{t} \neq G_{s}$ for some $t \neq s$ with probability greater than 0 . Appendix B provides a description of the test statistic and computational details. 


\subsection{Estimation}

The estimation procedure is based on the assumption of poolability over all the sample, or a subset for which we cannot reject the poolability hypothesis. We use the local linear kernel regression to estimate $\Psi\left(\mathbf{x}_{i t}\right)$ with $\mathbf{x}_{i t}=\left(x_{i t}, x_{j t-1}\right)^{\prime} .{ }^{8}$ The local linear (polynomial of order 1) kernel estimator performs better than the local constant (polynomial of order 0) kernel estimator or Nadaraya-Watson estimator, since it is less affected by the bias resulting from data asymmetry (notably at the boundaries of the sample).

Let $\mathbf{Y}$ denote the $N(T-1)$ vector of first differences $y_{i t}-y_{i t-1}$, the first $T-1$ elements of which correspond to the first country, and so on. Let $\mathbf{X}^{*}$ denote a $N(T-1) \times 2$ matrix, organized in the same way as $\mathbf{Y}$, with $\mathbf{x}_{i t}^{\prime}$ as typical row. We set $\mathbf{X}=\left(\iota, \mathbf{X}^{*}\right)$ where $\iota$ is a $N(T-1)$ vector of 1 . Let $K_{\mathbf{h}}($.$) be a multivariate$ kernel satisfying the usual regularity conditions, and $\mathbf{h}=\left(h_{1}, h_{2}\right)^{\prime}$, a $2 \times 1$ vector of bandwidths (or smoothing parameters) corresponding respectively to $x_{i t}$ and $x_{i t-1}$.

The idea of the local linear regression is to simultaneously estimate the value and the local slope of the conditional expectation, and this is done by performing what amounts to a weighted least squares local linear regression. Indeed the local linear estimator of $\Psi\left(\mathbf{x}_{0}\right)$ is given by

$$
\widehat{\Psi}\left(\mathbf{x}_{0}\right)=\mathbf{e}_{1}^{\prime}\left(\mathbf{X}^{\prime} \mathbf{Z}_{\mathbf{x}_{0}} \mathbf{X}\right)^{-1} \mathbf{X}^{\prime} \mathbf{Z}_{\mathbf{x}_{0}} \mathbf{Y}
$$

where $\mathbf{e}_{1}=(1,0,0)^{\prime}$, and $\mathbf{Z}_{\mathbf{x}_{0}}=\operatorname{diag}\left\{K_{\mathbf{h}}\left(\mathbf{X}_{1,1}^{*}-\mathbf{x}_{0}\right), \cdots, K_{\mathbf{h}}\left(\mathbf{X}_{N, T-1}^{*}-\mathbf{x}_{0}\right)\right\}$. It is well known that, compared to the selection of the bandwidths, the choice of the kernel is of minor importance for the properties of the resulting estimator. We use the product kernel $K_{\mathbf{h}}\left(\tau_{1}, \tau_{2}\right)=\frac{1}{h_{1}} K\left(\frac{\tau_{1}}{h_{1}}\right) \frac{1}{h_{2}} K\left(\frac{\tau_{2}}{h_{2}}\right)$ with $K$ the standard univariate Gaussian kernel. We use the least squares cross-validation method to select the bandwidths $\mathbf{h}$. This data-driven method is frequently used in the literature. See Wand and Jones (1995) for a discussion on the choice of smoothing parameters. ${ }^{9}$

Once $\widehat{\Psi}(\mathbf{x})$ is obtained by local linear kernel estimation, we use the marginal

\footnotetext{
${ }^{8}$ Härdle (1990) provides an extensive discussion of various nonparametric methods. Those based on kernel estimators include local polynomial kernel estimators.

${ }^{9}$ Since $x_{i t}$ and $x_{i, t-1}$ are similar variables, we choose $h_{1}=h_{2}$. Moreover, this choice facilitates the computational procedure and does save computational time. It should be noticed that the use of different values for $h_{1}$ and $h_{2}$ would allow to smooth by different amounts in each of two coordinate directions. The full $2 \times 2$ smoothing matrix (employed with a bivariate kernel in place of the product kernel function $K_{\mathbf{h}}$ ) would smooth in directions different from those of the two coordinate axes. However, both alternatives lead to an increasing time burden in computations (see Wand and Jones, 1995).
} 
integration method proposed by Linton and Nielsen (1995) to retrieve the individual functions $G\left(x_{i t}\right)$ and $G\left(x_{i t-1}\right)$. The main idea of this method can be described as follows. For simplicity, let us rename the arguments of $\widehat{\Psi}$ as $x$ and $y$. We can write

$$
\begin{aligned}
E_{y}[\widehat{\Psi}(x, Y)] & =\int \widehat{\Psi}(x, y) f(y) d y \\
& =G(x)-E_{y}[G(Y)] \\
& =G(x)-k,
\end{aligned}
$$

and similarly,

$$
\begin{aligned}
E_{x}[\widehat{\Psi}(X, y)] & =\int \widehat{\Psi}(x, y) f(x) d x \\
& =k-G(y)
\end{aligned}
$$

We thus obtain estimators of $G\left(x_{i t}\right)$ and $G\left(x_{i t-1}\right)$ up to the same constant by taking the sample averages

$$
\widehat{G}^{(1)}\left(x_{i t}\right)=\frac{1}{N(T-1)} \sum_{j=1}^{N(T-1)} \widehat{\Psi}\left(x_{i t}, x_{j}\right) .
$$

Similarly, we can obtain an estimator for $G\left(x_{i t-1}\right)$, i.e.

$$
\widehat{G}^{(2)}\left(x_{i t-1}\right)=-\frac{1}{N(T-1)} \sum_{j=1}^{N(T-1)} \widehat{\Psi}\left(x_{j}, x_{i t-1}\right) .
$$

A more precise estimator of $G$ can be obtained by a weighted average between $\widehat{G}^{(1)}$ and $\widehat{G}^{(2)}$, and a simple estimator is given by $\widehat{G}(x)=\left[\widehat{G}^{(1)}(x)+\widehat{G}^{(2)}(x)\right] / 2$.

\section{Data}

The data structure is a balanced panel of 100 countries over the period 1960-1996. The list of countries is provided in Appendix A. ${ }^{10}$ The series stem from three sources. The national $\mathrm{CO}_{2}$ emission per capita series, measured in metric tons, were provided by the Carbon Dioxide Information Analysis Center (CDIC) of the Oak Ridge National Laboratory (see Marland et al., 1999). The real GDP per capita series, measured in thousand constant dollars in 1985 international prices, were extracted from the Penn World Table 5.6 (Summers and Heston, 1991 ). Since the series for

\footnotetext{
${ }^{10}$ The balanced nature of the panel excludes countries with separation/reunification during the data collecting period (e.g., Russia and other former Soviet Republics, Germany).
} 
GDP per capita are available only until 1992 in the Penn World Table 5.6, the missing values were completed by the series of GDP per capita from the bases Global Development Finance and World Development Indicators. The $\mathrm{CO}_{2}$ series include emissions from fossil fuel burning, gas flaring and cement manufacture, but exclude emissions from bunker fuels used in international transport. More details on the data can be found in Holtz-Eakin and Selden (1995).

Table 1 provides descriptive statistics and takes account of the panel structure of the sample by reporting also between and within country magnitudes.

\section{Table 1}

$\mathrm{CO}_{2}$ emissions per capita vary from 0 (the level of, e.g., Chad in 1960) to 10.99 metric tons (the level of Luxembourg in 1970). GDP per capita varies from 126 (Congo Dem. Rep., former Zaire, in 1996) to 19,474 thousands of 1985 dollars (USA in 1996) for the overall statistic. The within patterns refer to deviation from each country's average over time. The between standard deviations for $\mathrm{CO}_{2}$ emissions and GDP are both approximately three times larger than their within counterparts.

Kernel density estimates for GDP per capita in 1960, 1980 and 1996 (Figure 1) indicate a bi-modal and highly skewed distribution in all periods. We observe that the proportion of low GDP per capita countries slightly decreases during the sampling period. However, while the left (and overall) mode remains more or less constant, the right mode increases considerably over time. In the subsequent section, the effect of this change in the distribution of per capita GDP on the functional form of $G_{t}$ is shown to be insignificant for the whole sample at hand.

\section{Figure 1}

\section{Estimation results}

This section first discusses the results related to model specification and then outlines the economic implications of the estimation results. ${ }^{11}$ In Subsection 5.1 we present the results of the nonparametric poolability test, the results of the nonparametric regression, and a monotonicity test. The latter does not reject monotonicity, and thus produces evidence against the existence of an $\mathrm{EKC}$ for $\mathrm{CO}_{2}$ emissions. In Subsection 5.2 we present parametric estimation and test results. Subsection 5.3 is devoted to the economic and environmental implications of these results.

\footnotetext{
${ }^{11}$ All the computations in this study were performed with GAUSS Version 6.0.
} 


\subsection{Poolability test and nonparametric regression}

The nonparametric poolability test statistic of Baltagi et al. (1996) is equal to -1.623 for the whole sample period, which is much lower than 1.645, the $95 \%$ quantile of the standard normal distribution. This means that there is no evidence for a structural shift in the relation between $\mathrm{CO}_{2}$ emissions and GDP per capita over the period of study (1960-1996). As a result, the retained nonparametric specification is

$$
y_{i t}=G\left(x_{i t}\right)+\mu_{i}+v_{i t},
$$

where the function $G$ does not depend on $t$. We now turn to the estimation of $G$. Writing equation (17) in first difference gives

$$
y_{i t}-y_{i t-1}=G\left(x_{i t}\right)-G\left(x_{i t-1}\right)+v_{i t}-v_{i t-1} .
$$

Using local linear kernel estimation and marginal integration as described in Subsection 3.2 and in Appendix B, we obtain the estimates of $G\left(x_{i t-1}\right)$ and $G\left(x_{i t}\right)$. We thus have two estimators for the same function, and a more precise estimator will be the simple average of the two, which we denote $\widehat{G}$. Figure 2 plots the graph of the corresponding estimate with bootstrap $95 \%$ pointwise confidence intervals. In the estimation procedure, the common bandwidth obtained by cross-validation is 1.92 . In order to construct the confidence intervals, we use the wild bootstrap with 1000 bootstrap samples. The wild bootstrap allows us to account for heteroskedasticity and autocorrelation between observations for a given country (see Appendix C for further details).

\section{Figure 2}

At first sight, the shape of $\widehat{G}(x)$ seems monotone. In order to formally test this assumption, we perform the monotonicity test of Bowman et al. (1998). See Appendix $\mathrm{D}$ for details. The null hypothesis is monotonicity. The intuition behind this test is that the monotonicity of the nonparametric estimate is less likely for small values of the bandwidth than for large values, since increasing the bandwidth leads to a smoother estimate. In fact, there is a critical bandwidth at which the estimate changes from the nonmonotonicity exhibited at all smaller bandwidths to monotonicity which persists for all larger bandwidths. As a result, if the null hypothesis of monotonicity is true, the critical bandwidth should be relatively small, whereas if monotonicity is false, the critical bandwidth needs to be larger to force monotonicity. Thus the idea of the test is (i) to find the critical bandwidth $h_{c}$ defined as the smallest value of the bandwidth that gives rise to regression monotonicity, i.e. $\widehat{G}\left(x, h_{c}\right)$ 
monotone in $x$, even if there exists a larger bandwidth for which the function is not monotone, and (ii) to construct the $p$-value of the test by bootstrap (here we use the wild bootstrap again). As a result, we obtain $h_{c}=1.1$ with a $p$-value $=0.173$ for $\widehat{G}(x)$. Therefore, we conclude that the relationship between $\mathrm{CO}_{2}$ emissions and per capita GDP is monotone. This clearly contradicts the existence of an EKC for $\mathrm{CO}_{2}$ emissions.

\subsection{Parametric specifications}

For comparison purposes, we also provide a parametric version of the result of the poolability test. We consider the model

$$
y_{i t}=\beta_{1} x_{i t}+\beta_{2} x_{i t}^{2}+\beta_{3} x_{i t}^{3}+\mu_{i}+v_{i t},
$$

where $\mu_{i}$ denotes a country effect. Efficient estimation of model (19) in the absence of further assumptions on the individual effects can be carried out by Ordinary Least Squares (OLS) on the data transformed by the within operator (i.e. centered on individual means), assuming strict exogeneity of GDP per capita, an assumption which we subsequently test. The $F$-test statistic for the null of absence of fixed countryspecific effects is $160.45>F_{(99,3579)}=1.25$ at the $5 \%$ level, implying rejection: fixed country-specific effects do exist. We also perform an $F$-test for the null of absence of fixed year effects in the presence of fixed country effects (see, e.g., Baltagi, 1995). ${ }^{12}$ The value of $F$-statistic is $0.79<F_{(36,3561)}=1.42$ at the $5 \%$ level. We can conclude that fixed year effects do not exist. Note that the nonexistence of fixed year effects is compatible with the result obtained by the nonparametric poolability test. We thus retain the parametric model (19) with country effects only. For the within estimator, we compute a variance matrix estimator which is robust to heteroskedasticity and serial correlation of unknown form (see, e.g., Arellano, 1987, and Wooldridge, 2002) . In the results for the within estimates, only linear and cubic terms of the GDP per capita are significant at the $5 \%$ level.

We also apply OLS on the first-difference version of model (19). Provided assumption (4) holds, the resulting estimator remains consistent even if strict exogeneity of GDP per capita does not hold, in contrast to the within estimator. Again, we compute a variance matrix estimator which is robust to heteroskedasticity and unrestricted serial correlation. Note that estimating first order correlation in the first difference residuals leads to a value of -0.022 with a robust $t$-value of -0.31 ,

\footnotetext{
${ }^{12}$ In this case, the model is $y_{i t}=x_{i t} \beta_{1}+x_{i t}^{2} \beta_{2}+x_{i t}^{3} \beta_{3}+\mu_{i}+\lambda_{t}+v_{i t}$ where $\mu_{i}$ and $\lambda_{t}$ indicate fixed country effects and fixed year effects, respectively.
} 
which supports assumption FDA (4) for the parametric model (since it is not in contradiction with a random walk for $v_{i t}$ ).

\section{Table 2}

Table 2 reports the parametric estimation results and Figure 3 depicts the corresponding relationships. A very interesting result is that, whereas within estimation gives an inverted U-shaped relationship between $\mathrm{CO}_{2}$ emissions per capita and GDP per capita, with a maximum well within the span of the data, the first-difference estimation gives a monotonous increasing relationship. A Hausman test based on robust variance estimators is performed to test strict exogeneity of GDP per capita on the basis of a comparison of the within and first-difference estimators. The value of the statistic is $275.32>\chi^{2}(3)=7.8$ at the $5 \%$ level, implying the rejection of the null hypothesis of strict exogeneity. However, given the finding of a random walk for the idiosyncratic error term, the first difference estimator is efficient under the null, which questions the validity of the Hausman test. Therefore we also test strict exogeneity on the basis of the first difference estimator alone, checking the significance of the current level of per capita GDP as an additional variable (see e.g. Wooldridge, 2002, p.285). The obtained $t$-value (based on the same robust variance estimate as above) is -2.91 , and it leads to clear rejection of strict exogeneity.

\section{Figure 3}

Our nonparametric result of a monotonous increasing relationship between $\mathrm{CO}_{2}$ emissions per capita and GDP per capita is consistent with the results obtained by Shafik (1994), Holtz-Eakin and Selden (1995), and Heil and Selden (2001), but contradicts those obtained by Roberts and Grimes (1997), Schmalensee et al. (1998), Sun (1999), and Taskin and Zaim (2000). Two major explanations for the difference between our parametric findings and those of Holtz-Eakin and Selden (1995) and Heil and Selden (2001) can be put forward. Firstly, we do not use the same data as those studies. The data used in Holtz-Eakin and Selden (1995) concern the period 1951 to 1992 , whereas our data are from 1960 to 1996. The second reason lies in the estimation method. When we use the first-difference estimator, we find a result consistent with that of Holtz-Eakin and Selden (1995), that is, a monotonous relationship. With the within estimator, we obtain an EKC. The latter is in line with the finding of Schmalensee et al. (1998) and Galeotti and Lanza (1999). However, the assumption yielding consistency of the within estimator, namely strict exogeneity of per capita GDP, is rejected. It is conceivable that the same kind of misspecification 
affects the conclusions of Aslanidis and Xepapadeas (2004) and Bertinelli and Strobl (2005), since they also use fixed-effects type estimators.

Next, we use the nonparametric specification test proposed by $\mathrm{Li}$ and Wang (1998) to check whether the parametric model in (19) can be rejected against the nonparametric model in (17). Details on the test can be found in Appendix E. The null hypothesis is the first-difference version of the parametric model in (19) and the alternative is (18). The statistic for this one-sided test has an asymptotic standard normal distribution under the null of correct specification of the parametric model. ${ }^{13}$ This is computed as 11.12, much higher than 1.65, the value of the standard normal distribution at the $5 \%$ level. Therefore, we reject the parametric specification in favour of the nonparametric model. We also performed the Li and Wang test for the first difference model with a linear term only. The test statistic is 4.74 , which still leads to a rejection. Given the confidence bands shown in Figure 2, this rejection may seem surprising, since it appears easy to fit a straight through these. However the alternative in the test is the expectation of the first difference in $\mathrm{CO}_{2}$ emissions given GDP and lagged GDP (see equation (18)). This may be considered a too flexible alternative. Yet the alternative based on conditioning on the first differences in the three powers of GDP is not attractive. We thus also performed the Li and Wang test for the first difference model with the three powers of GDP, using $\mathrm{E}\left[\Delta \mathrm{CO}_{2} \mid \Delta \mathrm{GDP}\right]$ as the alternative. The test statistic is 5.16 , which still leads to a rejection of the parametric model.

As a whole, the analysis underlines the importance of functional specification and estimation method. First-difference and nonparametric estimations produce similar results, and perform significantly better than within estimation. The latter is consistent only in the case where strict exogeneity assumption holds, and this is rejected by our data.

\subsection{Economic and environmental implications}

How can we explain the monotonous relation between $\mathrm{CO}_{2}$ emissions per capita and economic development obtained in this study? Several arguments can be put forward. The earlier stage of economic development are associated with comparatively

\footnotetext{
${ }^{13}$ The test proposed by Li and Wang (1998) works for models with no serial correlation. If the idiosyncratic error term in the parametric model is a random walk, i.e. $v_{i t}=v_{i t-1}+\eta_{i t}$ where $\eta_{i t}$ is a white noise, first-differencing will eliminate the serial correlation. This is then consistent with our framework. Li and Wang (1998) also note that the normal approximation for the test statistic does not work well for small or moderate samples. But as our sample contains 3600 observations after first-differencing, we can have some confidence in the asymptotic version of this test.
} 
slow economic activities. One may think that at such a stage, obsolete technologies are still used. At the same time, government policies are more aimed at economic development than at environmental protection. Consequently, $\mathrm{CO}_{2}$ emissions rise with economic activities. In rich countries, the positive effect on emissions due to intensive economic activities seems to exceed the reduction in emissions due to the use of modern technologies. On the whole, the economic development process always results in increased $\mathrm{CO}_{2}$ emissions.

As regards policy concerns, our results suggest that not only poor countries, but also richer countries, face environmental pollution. It implies that economic development is not a sufficient condition to reduce $\mathrm{CO}_{2}$ emissions, and so all countries, especially developed countries because of their important resources (financial, technological, etc.), should make an effort to reduce these emissions in order to reduce global warming.

This study focuses on one particular type of environmental problem, $\mathrm{CO}_{2}$ emissions. The question arises whether or not our results are specific to $\mathrm{CO}_{2}$. An answer to this question can only be obtained by using data relating to these pollutants. Before embarking on such a task, it seems of more direct interest to discuss the specificity of $\mathrm{CO}_{2}$ in order to underline both the limits and the contributions of our study.

The question of the specificity of $\mathrm{CO}_{2}$ can be articulated in two ways: the complementarity of the production factors and restrictions on energy substitution on the one hand, and the deceleration of the efforts of energy saving on the other hand. The problem of $\mathrm{CO}_{2}$ emissions is directly related to that of energy use, and there is a strong correlation between fossil energy use, $\mathrm{CO}_{2}$ emissions, and economic activity. The specificity of $\mathrm{CO}_{2}$ follows from the fact that there is a level of $\mathrm{CO}_{2}$ emissions related to economic activity which cannot be reduced, and that economic activity cannot be reduced to zero. Thus, $\mathrm{CO}_{2}$ emissions are much more difficult to reduce than other gas emissions. This may be a reason for the unwillingness of some countries to contribute to $\mathrm{CO}_{2}$ reduction under a given threshold (this is particularly revealing in the current debate about the Kyoto protocol). Indeed, that would automatically have a detrimental effect on their economic activities. This may be also an explanation for the monotonous curve obtained from the nonparametric model. The question of the determination of a threshold and its modulation country by country during a period of time remains unsolved. The efforts to be made will directly depend on this threshold.

Therefore, we observe a difficulty of $\mathrm{CO}_{2}$ abatement. This is due to the absence 
of incentives to save energy and to use less polluting or renewable energies, which is related to energy substitution. New green technologies are costly to use. At the present stage of technology, renewable energies cannot be produced in large quantities, and thus are not profitable. The debate concerning the deceleration of energy-saving efforts is well-known. Indeed, since the two oil crises, the real price of an oil barrel has not ceased to fall until very recently. Thus there seems to be no incentive on behalf of the political leaders to carry out energy-saving policies and to reduce $\mathrm{CO}_{2}$ emissions. In order to reduce $\mathrm{CO}_{2}$ emissions in the future, public policy should create incentives for energy saving and encourage the use of renewable energies and new green technologies.

\section{Conclusion}

This paper investigates the empirical relationship between $\mathrm{CO}_{2}$ emissions and economic development using an international panel data set. We find evidence supporting specifications which assume the stability of the relationship between $\mathrm{CO}_{2}$ emissions per capita and GDP per capita over time during the period of the study. We show that within estimation of a parametric specification yields an EKC, but that the underlying strict exogeneity assumption of per capita GDP is rejected, whereas both the nonparametric and the first-difference estimations clearly contradict the existence of an $\mathrm{EKC}$ for $\mathrm{CO}_{2}$ emissions. Still, it also turns out that the parametric model is rejected against the nonparametric specification.

An extension of this study would be to introduce a country-specific trend in the model. Another natural extension would be to investigate a VAR-type model for $\mathrm{CO}_{2}$ emissions and per capita GDP, and to analyse the long-run and shortrun effects of GDP. However, accounting for this in a nonparametric context is by no means trivial. Finally, structural nonparametric modelling (which incorporates potential endogeneity problems) may also deserve more attention.

Our study can be replicated on other environmental indicators like to urban air pollution, deforestation, water quality, etc. in order to settle the animated but often also unedifying debate on the form of relationship between environmental quality and growth which arises from the use of parametric models. The important policy implications of this apparently purely methodological point cannot be overstated. 


\section{Appendix A: list of countries}

Table A: List of countries and types of $\mathrm{CO}_{2}-\mathrm{GDP}$ profiles.

\begin{tabular}{llll}
\hline \hline 2 Algeria & 2 Dominican Rep. & 1 Ivory Coast & 2 Philippines \\
1 Angola & 2 Ecuador & 2 Jamaica & 2 Portugal \\
2 Argentina & 2 Egypt & 5 Japan & 3 Romania \\
2 Australia & 2 El Salvador & 3 Jordan & 3 Saudi Arabia \\
3 Austria & 1 Ethiopia & 1 Kenya & 2 Senegal \\
5 Belgium & 1 Fiji & 2 Korean Rep. & 5 Seychelles \\
2 Belize & 3 Finland & 6 Luxembourg & 1 Sierra Leone \\
1 Benin & 4 France & 3 Madagascar & 2 Singapore \\
2 Bermuda & 3 Gabon & 1 Mali & 2 South Africa \\
2 Bolivia & 2 Gambia & 3 Malta & 2 Spain \\
2 Brazil & 1 Ghana & 1 Mauritania & 1 Sri Lanka \\
2 Burkina Faso & 2 Greece & 2 Mauritius & 1 Sudan \\
2 Cameroon & 2 Guatemala & 2 Mexico & 4 Sweden \\
4 Canada & 1 Guinea & 2 Morocco & 4 Switzerland \\
1 Cape Verde & 1 Guinea-Bissau & 2 Mozambique & 2 Syria \\
1 Central African Rep. & 1 Haiti & 2 Nepal & 2 Thailand \\
1 Chad & 3 Honduras & 5 Netherlands & 1 Togo \\
2 Chile & 3 Hong Kong & 2 New Zealand & 3 Trinidad \& Tobago \\
2 China & 3 Hungary & 2 Nicaragua & 2 Tunisia \\
2 Colombia & 4 Iceland & 1 Niger & 2 Turkey \\
1 Comoro & 2 India & 3 Nigeria & 1 Uganda \\
2 Congo Democratic Rep. & 2 Indonesia & 2 Norway & 6 United Kingdom \\
1 Congo Rep. & 2 Ireland & 1 Papua New Guinea & 5 United States \\
2 Costa Rica & 2 Israel & 2 Paraguay & 1 Uruguay \\
3 Denmark & 2 Italy & 2 Peru & 6 Venezuela \\
\hline \hline
\end{tabular}

Note: the numbers refer to types of $\mathrm{CO}_{2}-\mathrm{GDP}$ profiles. 1. flat; 2. increasing; 3. increasing then flat; 4. inverted U; 5 . N shape; 6 . decreasing. 


\section{Appendix B: poolability test}

Let us consider the following nonparametric regression for panel data:

$$
y_{i t}=g_{t}\left(x_{i t}\right)+u_{i t}
$$

with $i=1, \ldots, N, t=1, \ldots, T$, where independence across individuals $i$ is assumed as well as mean independence of $u_{i t}$ from $x_{i t}$. Moreover the $u_{i t}$ are assumed uncorrelated over time. The poolability test aims to test the assumption $g_{t}=g$ for all $t$ against the alternative $H_{1}: g_{t} \neq g$ for some $t$. The parametric analogue of this test is the well-known Chow test. However, as pointed out by Baltagi et al.(1996), the Chow test is based on parametric specifications and it is not clear whether a rejection of the null follows from a non constancy of parameters over time or if it is due to a misspecification problem.

The relationship between this framework and the one described in Section 3.1 is the following. Rewriting equation (1) as

$$
y_{i t}=\left(G_{t}\left(x_{i t}\right)+E\left[\mu_{i} \mid x_{i t}\right]\right)+\left(\mu_{i}-E\left[\mu_{i} \mid x_{i t}\right]+\nu_{i t}\right),
$$

yields the identification $g_{t}\left(x_{i t}\right)=G_{t}\left(x_{i t}\right)+E\left[\mu_{i} \mid x_{i t}\right]$ and $u_{i t}=\mu_{i}-E\left[\mu_{i} \mid x_{i t}\right]+\nu_{i t}$, where $E\left[u_{i t} \mid x_{i t}\right]=0$ by construction. Under the supplementary and not unreasonable assumption that $E\left[\mu_{i} \mid x_{i t}\right]$, as a function of $x_{i t}$ does not depend on $t$, we obtain the equivalence between the assumptions $g_{t}=g$ for all $t$ and $G_{t}=G$ for all $t$.

The test statistic is given by

$$
J=\frac{N b^{1 / 2} I}{\sqrt{2 \hat{\sigma}_{0}^{2}}}
$$

where

$$
I=\frac{1}{N(N-1) T b} \sum_{t} \sum_{i} \sum_{j \neq i}\left(\hat{u}_{i t} \hat{f}_{i t}\right)\left(\hat{u}_{j t} \hat{f}_{j t}\right) K_{b}\left(x_{i t}-x_{j t}\right)
$$

and

$$
\hat{\sigma}_{0}^{2}=\frac{1}{T^{2}} \sum_{t}\left[\frac{1}{N(N-1) b} \sum_{i} \sum_{j \neq i}\left(\hat{u}_{i t} \hat{f}_{i t}\right)^{2}\left(\hat{u}_{j t} \hat{f}_{j t}\right)^{2} K_{b}^{2}\left(x_{i t}-x_{j t}\right)\right],
$$

with $\hat{u}_{i t}=y_{i t}-\hat{y}_{i t}$ denoting the nonparametric residual from the pooled model (under $\left.\mathrm{H}_{0}\right)$, and $\hat{f}_{i t}=\frac{1}{N T a} \sum_{j} \sum_{s} K_{a}\left(x_{i t}-x_{j s}\right)$ denoting the kernel density estimate for the pooled data. $K_{r}=K(\dot{\bar{r}})$ denotes the kernel function corresponding to the bandwidth $r$ where $r=a, b$. So $K_{a}$ and $K_{b}$ are respectively the kernel functions corresponding to the pooled data for the whole period of the study and the $N$-cross 
sectional data for a fixed value of $t$. We use a standard Gaussian kernel. In order to select the bandwidths, we use a data-driven method, least squares cross-validation.

The computation of $a$ is based on the pooled data. As regards $b$, we first compute a bandwidth $b_{t}$ for each cross-section separately, and set $b$ to the minimum of the $b_{t}$. With this choice, the condition that $\left(b^{2} / a\right) \rightarrow 0$ (see Baltagi et al., 1996) appears to be satisfied, as we obtain $a=0.6$ and $b=0.1$, and thus $\left(b^{2} / a\right)<0.02 .{ }^{14}$

$J$ has a standard normal distribution under $\mathrm{H}_{0}$. Under $\mathrm{H}_{1}, J \stackrel{p}{\longrightarrow} J_{0}>0$. Thus, the poolability test is one-sided. To compute the test statistic, Baltagi et al. (1996) used the Nadaraya-Watson kernel estimator for estimating $\hat{y}_{i t}=E\left[y_{i t} \mid x_{i t}\right]$. Here we use the local linear kernel estimator as it has a better behaviour at the boundaries. The estimator is then similar to the one given in (9), except that we are now in the univariate case.

\section{Appendix C: the wild bootstrap}

Several bootstrap methods are available (see, e.g., Horowitz, 2001). To construct the confidence bands for nonparametric estimators as well as the critical values of the nonparametric tests, we use the wild bootstrap as now described. Let us consider the nonparametric regression model

$$
y=m(x)+\epsilon,
$$

where $m(x)$ represents a unknown function of $x$, whose nonparametric estimator is denoted $\hat{m}(x, h), h$ being the smoothing parameter. Let us denote by $\hat{\epsilon}=y-\hat{m}(x, h)$ the regression residuals. The different steps of the wild bootstrap algorithm are the following:

$s=1$

\section{Repeat}

Step 1: Generate the bootstrap errors $\epsilon^{*}$ using the two points distribution probability: $P\left(\epsilon^{*}=\hat{\epsilon} \lambda\right)=\delta ; P\left(\epsilon^{*}=\hat{\epsilon} \mu\right)=1-\delta$, with $\lambda=$ $(1-\sqrt{5}) / 2, \mu=(1+\sqrt{5}) / 2, \delta=(5+\sqrt{5}) / 10$.

Step 2: Generate new bootstrap samples $y^{*}=\hat{m}\left(x, h_{b}\right)+\epsilon^{*}$, where $h_{b}$ is the bandwidth slightly greater than $h$. Then, $\hat{m}\left(x, h_{b}\right)$ is slightly over-smoothed compared to $\hat{m}(x, h)$. Compute $\hat{m}^{*}(x, h)$, that is the nonparametric estimator applied to the bootstrap sample $\left\{y^{*} ; x\right\}$.

\footnotetext{
${ }^{14}$ Thanks to $\mathrm{Qi} \mathrm{Li}$ for a private communication approving this choice.
} 
$s=s+1$

Until $s=B$ (number of bootstrap samples, here we set $B=1000$ ).

In order to compute the pointwise bootstrap confidence interval of level $(100-\alpha)$ for $\hat{m}(x, h)$, we define the lower and upper bounds as the $(\alpha / 2)$ th and $(100-\alpha / 2)$ percentiles of the distribution of the bootstrap estimators $\left\{\hat{m}^{*}(x, h)\right\}$, respectively.

Remark 1 The wild bootstrap yields estimations which account for heteroskedasticity and correlation between observations. This can be easily observed from the resulting covariance structure. Indeed, let $\hat{u}_{n}$ denote a random variable, and $u_{n}^{*}$ the associate bootstrap sample, where $u_{n}^{*}$ has realization probabilities $p$ and $1-p$ corresponding to $\beta \hat{u}_{n}$ and $\gamma \hat{u}_{n}$, respectively. Then, we can write, from the covariance decomposition, $\operatorname{cov}\left(u_{i}^{*}, u_{j}^{*}\right)=E\left[\operatorname{cov}\left(u_{i}^{*}, u_{j}^{*}\right) \mid \hat{u}_{i}, \hat{u}_{j}\right]+\operatorname{cov}\left[E\left(u_{i}^{*} \mid \hat{u}_{i}, \hat{u}_{j}\right), E\left(u_{j}^{*} \mid \hat{u}_{i}, \hat{u}_{j}\right)\right]$. Since $E\left[\operatorname{cov}\left(u_{i}^{*}, u_{i}^{*}\right) \mid \hat{u}_{i}, \hat{u}_{j}\right]=0$; and $E\left(u_{k}^{*} \mid \hat{u}_{i}, \hat{u}_{j}\right)=\hat{u}_{k}, k=i, j$, we obtain $\operatorname{cov}\left(u_{i}^{*}, u_{j}^{*}\right)=\operatorname{cov}\left(\hat{u}_{i}, \hat{u}_{j}\right)$.

Remark 2 Another advantage of the bootstrap in constructing confidence intervals is that it avoids the computation of constants such as the bias of the estimator (see Härdle, 1990).

Remark 3 Other types of bootstrap confidence intervals can be used (for example, uniform confidence intervals) but their computation is not trivial.

\section{Appendix D: monotonicity test}

This test was proposed by Bowman et al. (1998). We use it as follows. Let $\hat{G}(x, h)$ be an individual function obtained by marginal integration with $h$ the bandwidth. We add $h$ in this functional notation for a better understanding of the test. We first determine the critical bandwidth $h_{c}$ as the smallest value of the bandwidth that gives rise to regression monotonicity, i.e. $\hat{G}\left(x, h_{c}\right)$ monotone, even if there exists a larger bandwidth for which the function is not monotone. As stated in Section 5.1, increasing the bandwidth leads to a smoother estimate. If we let the bandwidth grow indefinitely, the estimate becomes flat, and thus monotonous in the wide sense. This guarantees the existence of a bandwidth for which the estimated curve is monotonic. Then we construct the $p$-value of the test by bootstrap (here we use the wild bootstrap). The test is implemented as follows:

$$
k=1
$$




\section{Repeat}

Step 1: Find the critical bandwidth $h_{c}$ which is the smallest value of bandwidth such that $\hat{G}\left(x, h_{c}\right)$ is monotone, regardless of whether $\hat{G}\left(x_{i t}, h_{m}\right)$ might be non-monotone for some $h_{m}>h_{c}$.

Step 2: Compute $\hat{\varepsilon}_{i t}=\triangle y_{i t}-\hat{\Psi}\left(\mathbf{x}_{t}, \mathbf{h}\right)$, where $\triangle y_{i t}=y_{i t}-y_{i, t-1}$, $\hat{\Psi}\left(\mathbf{x}_{t}, \mathbf{h}\right)=\hat{G}^{(1)}\left(x_{i t}, h_{1}\right)-\hat{G}^{(2)}\left(x_{i, t-1}, h_{2}\right)$ and $\mathbf{h}=\left(h_{1}, h_{2}\right)^{\prime}$ is obtained by least squares cross-validation, as described in the text. We have chosen $h_{1}=h_{2}$.

Step 3: Generate a bootstrap sample $\hat{\varepsilon}_{i t}^{*}$ from $\hat{\varepsilon}_{i t}$ using the two-point distribution with $P\left(\varepsilon_{i t}^{*}=\hat{\varepsilon}_{i t} \beta\right)=\delta, P\left(\varepsilon_{i t}^{*}=\hat{\varepsilon}_{i} \gamma\right)=1-\delta$, where $\beta=$ $(1-\sqrt{5}) / 2, \gamma=(1+\sqrt{5}) / 2, \delta=(5+\sqrt{5}) / 10$. Construct new observations $\triangle y_{i t}^{*}=\hat{\Psi}\left(\mathbf{x}_{t}, \mathbf{h}_{c}\right)+\hat{\varepsilon}_{i t}^{*}$, where $\mathbf{h}_{c}=\left(h_{c, 1}, h_{c, 2}\right)^{\prime}$.

Step 4: Compute $\hat{\Psi}^{*}\left(\mathbf{x}_{t}, \mathbf{h}_{c}\right)$ using the bootstrap sample generated in Step 3 and observe whether or not the result is monotone for the function of interest.

$k=k+1$

Until $k>B$ (= number of bootstrap samples, here we set $B=1000)$.

Finally, construct the $p$-value by determining the proportion of estimates at Step 4 which are not monotonic.

\section{Appendix E: specification test}

The statistic test of Li and Wang (1998) is used in testing the parametric specification (19) against the nonparametric alternative (17). The test is based on the residuals of the parametric first-difference model. The underlying idea is that if the parametric model satisfactorily tracks the conditional expectation $E[y \mid x]$, the covariance between the error term $u$ and $E[y \mid x]$ should be zero. Equivalently, the covariance between $u$ and $E[u \mid x]$ should be zero. The test statistic is thus based on the following magnitude $I$ which is the empirical counterpart of $E[u E[u \mid x]]$. The test statistic is

$$
\begin{aligned}
I & =\frac{1}{n} \sum_{i=1}^{n} \hat{u}_{i}\left[\frac{1}{n h^{q}} \sum_{j=1, j \neq i}^{n} \hat{u}_{j} K_{h}\left(\mathbf{x}_{i}-\mathbf{x}_{j}\right)\right] \\
& =\frac{1}{n^{2} h^{q}} \sum_{i=1}^{n} \sum_{j=1, j \neq i}^{n} \hat{u}_{i} \hat{u}_{j} K_{h}\left(\mathbf{x}_{i}-\mathbf{x}_{j}\right),
\end{aligned}
$$


where $n=N(T-1), \mathbf{x}=\left(x, x_{-1}\right)^{\prime}$ with $x_{-1}$ being the one-period lag of $x, q=2$ (dimension of $\mathbf{x}$ ), and $\hat{u}$ is the parametric residuals of the first-difference model. $K_{h}\left(\tau_{1}, \tau_{1}\right)=K\left(\frac{\tau_{1}}{h}\right) K\left(\frac{\tau_{2}}{h}\right)$ is the kernel function and $h$ is the smoothing parameter obtained by least squares cross-validation. Under $\mathrm{H}_{0}, n h^{q / 2} I \rightarrow N(0, \Omega)$ in distribution as $n \rightarrow \infty$, where $\Omega=2\left[\int K^{2}(u) \mathrm{d} u\right] E\left[f(x) \sigma^{4}(\mathbf{x})\right] . \Omega$ is consistently estimated by $\hat{\Omega}=\left(2 /\left(n^{2} h^{q}\right)\right) \sum_{i} \sum_{j \neq i} \hat{u}_{i}^{2} \hat{u}_{j}^{2} K_{i j}^{2}$, where $K_{i j}=K_{h}\left(\mathbf{x}_{i}-\mathbf{x}_{j}\right)$. It follows that $J:=n h^{q / 2} I / \sqrt{\hat{\Omega}} \rightarrow N(0,1)$ in distribution. 


\section{References}

Arellano, M. (1987): "Computing Robust Standard Errors for Within-Group Estimators," Oxford Bulletin of Economics and Statistics, 49, 431-434.

Arellano, M., and B. Honoré (2001): "Panel Data Models: Some Recent Developments," in Handbook of Econometrics, ed. by J. J. Heckman, and E. Leamer, chap. 53. North Holland, Elsevier Science, Amsterdam.

Aslanidis, N., and A. Xepapadeas (2004): "Smooth Transition Pollution-income Paths," mimeo, University of Crete.

Baltagi, B. H. (1995): Econometric Analysis of Panel Data. John Wiley \& Sons, Chichester.

Baltagi, B. H., J. Hidalgo, And Q. Li (1996): "A Nonparametric Test for Poolability Using Panel Data," Journal of Econometrics, 75, 345-367.

Bertinelli, L., And E. Strobl (2005): "The Environmental Kuznets Curve SemiParametrically Revisited," Economics Letters, 88, 350-357.

Bowman, A. W., M. C. Jones, and I. Gijbels (1998): "Testing Monotonicity of Regression," Journal of Computational and Graphical Statistics, 7, 489-500.

Dasgupta, S., B. Laplante, H. Wang, and D. Wheeler (2002): "Confronting the Environmental Kuznets Curve," Journal of Economic Perspectives, 16, 147168.

Dijkgraaf, E., B. Melenberg, and H. R. J. Vollebergh (2005): "Environmental Kuznets Curves for $\mathrm{CO}_{2}$ : Homogeneity vs. Heterogeneity," CentER Discussion Paper 2005.25.

DijkgraAf, E., And H. R. J. Vollebergh (2005): "A Note on Testing for Environmental Kuznets Curves with Panel Data," forthcoming in Environmental and Resource Economics.

Galeotti, M., and A. Lanza (1999): "Richer and Cleaner? A Study on Carbon Dioxide Emissions in Developing Countries," Energy Policy, 27, 565-573.

Grossman, G. M., and A. B. Krueger (1993): "Environmental Impacts of a North American Free Trade Agreement," in The U.S.-Mexico Free Trade Agreement, ed. by P. Garber, pp. 165-177. MIT Press, Cambridge, MA. 
(1995): "Economic Growth and the Environment," Quarterly Journal of Economics, 60, 353-377.

Harbaugh, W. T., A. Levinson, and D. M. Wilson (2002): "Reexamining the Empirical Evidence for an Environmental Kuznets Curve," The Review of Economics and Statistics, 84, 541-551.

Heil, M. T., and T. M. Selden (2001): "Carbon Emissions and Economic Development: Future Trajectories Based on Historical Experience," Environment and Development Economics, 6, 63-83.

Hettige, H., M. Mani, and D. Wheeler (2000): "Industrial Pollution in Economic Development: the Environmental Kuznets Curve Revisited," Journal of Development Economics, 62, 445-476.

Holtz-Eakin, D., and T. M. Selden (1995): "Stoking the Fires? $\mathrm{CO}_{2}$ Emissions and Economic Growth," Journal of Public Economics, 57, 85-101.

Horowitz, J. L. (2001): "The Bootstrap," in Handbook of Econometrics, ed. by J. J. Heckman, and E. Leamer, chap. 52. North Holland, Elsevier Science, Amsterdam.

Härdle, W. (1990): Applied Nonparametric Regression. Cambridge University Press, Cambridge, New York.

Kaufmann, R. K., B. Davidsdottir, S. Garnham, and P. Pauly (1998): "The Determinants of Atmospheric $\mathrm{SO}_{2}$ Concentrations: Reconsidering the Environmental Kuznets Curve," Ecological Economics, 25, 209-220.

Koop, G., and L. Tole (1999): "Is There an Environmental Kuznets Curve for Deforestation?," Journal of Development Economics, 58, 231-244.

Levinson, A. (2002): "The Ups and Downs of the Environmental Kuznets Curve," in Recent Advances in Environmental Economics, ed. by J. List, and A. de Zeeuw. Edward Elgar: Cheltenham.

LI, Q., AND S. WANG (1998): "A Simple Consistent Bootstrap Test for a Parametric Regression Function," Journal of Econometrics, 87, 145-165.

Linton, O., And J. P. Nielsen (1995): "A Kernel Method of Estimating Structured Nonparametric Regression Based on Marginal Integration," Biometrika, 82, 93100. 
List, J. A., and C. A. Gallet (1999): "The Environmental Kuznets Curve: Does One Size Fit All?," Ecological Economics, 31, 409-423.

Marland, G., R. J. Andres, T. A. Boden, C. A. Johnston, and A. L. Brenkert (1999): "Global, Regional, and National $\mathrm{CO}_{2}$ Emission Estimates from Fossil Fuel Burning, Cement Production, and Gas Flaring: 1751-1996," Carbon Dioxide Information Analysis Center, Oak Ridge National Laboratory, U.S. Department of Energy, Oak Ridge, Tennessee, U.S.A.

Millimet, D. L., J. A. List, and T. Stengos (2003): "The Environmental Kuznets Curve: Real Progress or Misspecified Models?," Review of Economics and Statistics, 85, 1038-1047.

Millimet, D. L., And T. Stengos (2000): "A Semiparametric Approach to Modelling the Environmental Kuznets Curve Across US States," Department of Economics working paper, Southern Methodist University.

Panayotou, T. (2000a): "Population and Environment," CID working paper no. 54, Harvard University.

(2000b): "Population and Environment," in The International Yearbook of Environmental and Resource Economics 2000/2001: A Survey of Current Issues, ed. by T. Tietenberg, and H. Folmer, chap. 4. Edward Elgar, Cheltenham.

Roberts, J. T., and P. E. Grimes (1997): "Carbon Intensity and Economic Development 1962-91: A Brief Exploration of the Environmental Kuznets Curve," World Development, 25, 191-198.

Roy, N., And G. C. van Kooten (2004): "Another Look at the Income Elasticity of Non-point Source Air Pollutants: A Semiparametric Approach," Economics Letters, 85, 17-22.

Schmalensee, R., T. M. Stoker, and R. A. Judson (1998): "World Carbon Dioxide Emissions: 1950-2050," Review of Economics and Statistics, 80, 15-27.

Selden, T. M., And D. Song (1994): "Environmental Quality and Development: Is There a Kuznets Curve for Air Pollution Emissions ?," Journal of Environmental Economics and Management, 27, 147-162.

Shafik, N. (1994): "Economic Development and Environmental Quality: An Econometric Analysis," Oxford Economic Papers, 46, 757-773. 
Stern, D. I. (1998): "Progress on the Environmental Kuznets Curve?," Environmental and Development Economics, 3, 173-196.

(2004): "The Environmental Kuznets Curve," in Encyclopedia of Energy, ed. by C. J. Cleveland. Academic Press, San Diego CA, Cambridge, MA, chapter 5 .

Stern, D. I., And M. S. Common (2001): "Is There an Environmental Kuznets Curve for Sulphur?," Journal of Environmental Economics and Management, 41, $162-178$.

Summers, R., And A. Heston (1991): "The Penn World Table (Mark V): An Expanded Set of International Comparisons, 1950-1988," Quarterly Journal of Economics, 106, 327-369.

Sun, J. W. (1999): "The Nature of $\mathrm{CO}_{2}$ Emissions Kuznets Curve," Energy Policy, 27, 691-694.

Suri, V., And D. Chapman (1998): "Economic Growth, Trade and Energy: Implication for the Environmental Kuznets Curve," Ecological Economics, 25, 195-208.

Taskin, F., And O. Zaim (2000): "Searching for a Kuznets Curve in Environmental Efficiency Using Kernel Estimation," Economics Letters, 68, 217-223.

Wand, M. P., and M. C. Jones (1995): Kernel Smoothing. Chapman \& Hall, London.

Wooldridge, J. M. (2002): Econometric Analysis of Cross Section and Panel Data. MIT Press, Cambridge, MA. 
Table 1: Descriptive statistics

\begin{tabular}{|c|c|c|c|c|c|}
\hline Variables & & Mean & Std.dev. & Min. & Max. \\
\hline \multicolumn{6}{|c|}{$\mathrm{CO}_{2}$ emissions per capita (metric tons) } \\
\hline & overall & 0.937 & 1.371 & 0 & 10.99 \\
\hline & between & & 1.307 & 0.007 & 8.300 \\
\hline & within & & 0.432 & -1.932 & 4.238 \\
\hline \multicolumn{6}{|c|}{ GDP per capita (thousands $\$ 1985$ ) } \\
\hline & overall & 4.134 & 4.218 & 0.216 & 19.474 \\
\hline & between & & 3.932 & 0.305 & 14.825 \\
\hline & within & & 1.573 & -2.438 & 13.829 \\
\hline \multicolumn{6}{|c|}{100 countries } \\
\hline 37 years & & & & & \\
\hline
\end{tabular}

Table 2: Parametric estimation results

\begin{tabular}{|c|c|c|c|c|}
\hline \multirow[b]{2}{*}{ Variables } & \multicolumn{2}{|c|}{ Within } & \multicolumn{2}{|c|}{ First-difference } \\
\hline & Coef. & $t-$ stat. & Coef. & $t$-stat \\
\hline Linear term & $2.401^{*}$ & 7.25 & 0.275 & 0.52 \\
\hline Quadratic term & 0.570 & 1.08 & $1.791^{*}$ & 2.14 \\
\hline Cubic term & $-0.733^{*}$ & -3.22 & $-0.649^{*}$ & -2.03 \\
\hline
\end{tabular}

Notes. Dependent variable is $\mathrm{CO}_{2}$ emissions per capita (metric tons). Per capita GDP is expressed here in 10,000 $\$ 1985$. $t$-statistics are based on standard error estimates robust to both heteroskedasticity and serial correlation of unknown form. Significant coefficients at the $5 \%$ level starred. 


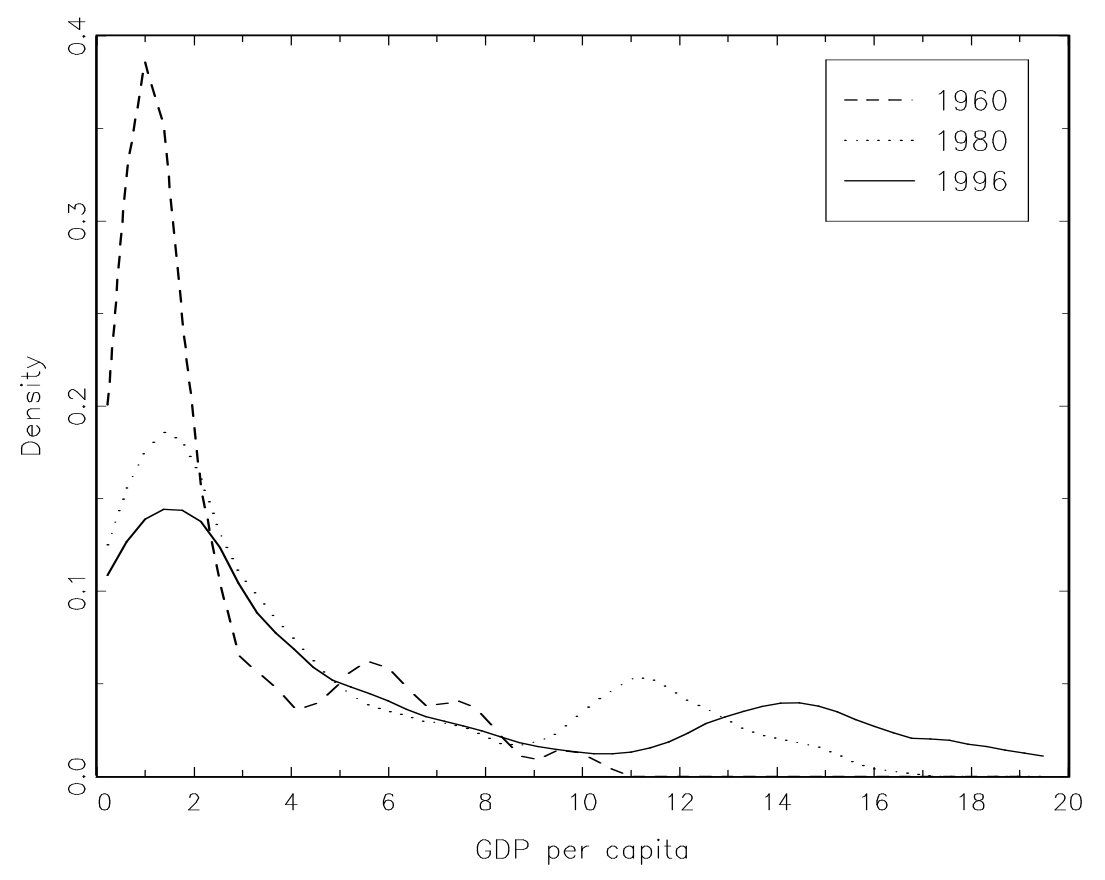

Figure 1: Kernel density estimate for GDP per capita in 1960, 1980, and 1996 using the Epanechnikov kernel. 


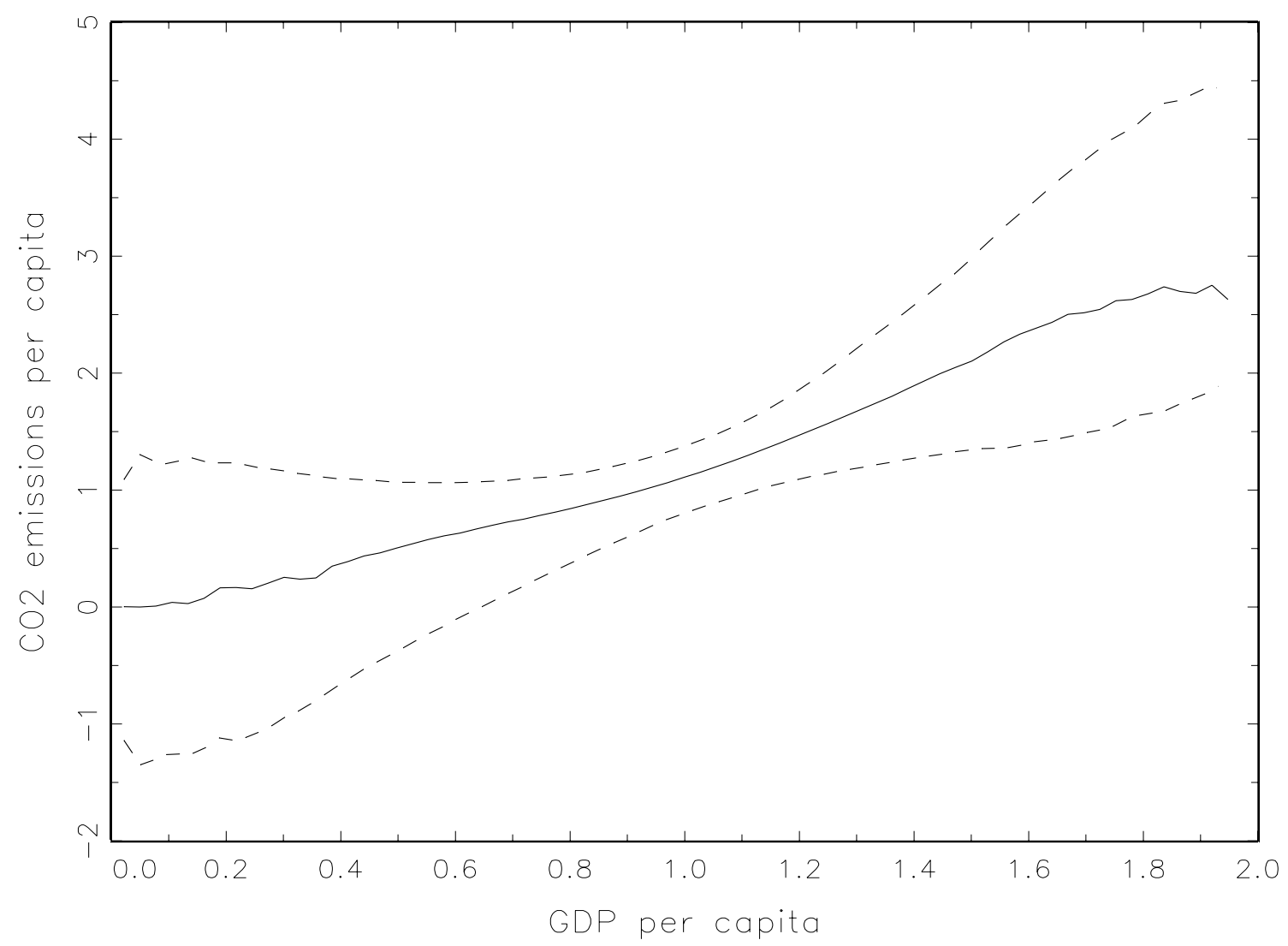

Figure 2: Nonparametric estimation of the relationship between $\mathrm{CO}_{2}$ emissions and GDP per capita. The solid curve represents $\widehat{G}$. The dashed curves correspond to upper and lower bootstrap 95\% pointwise confidence intervals. 


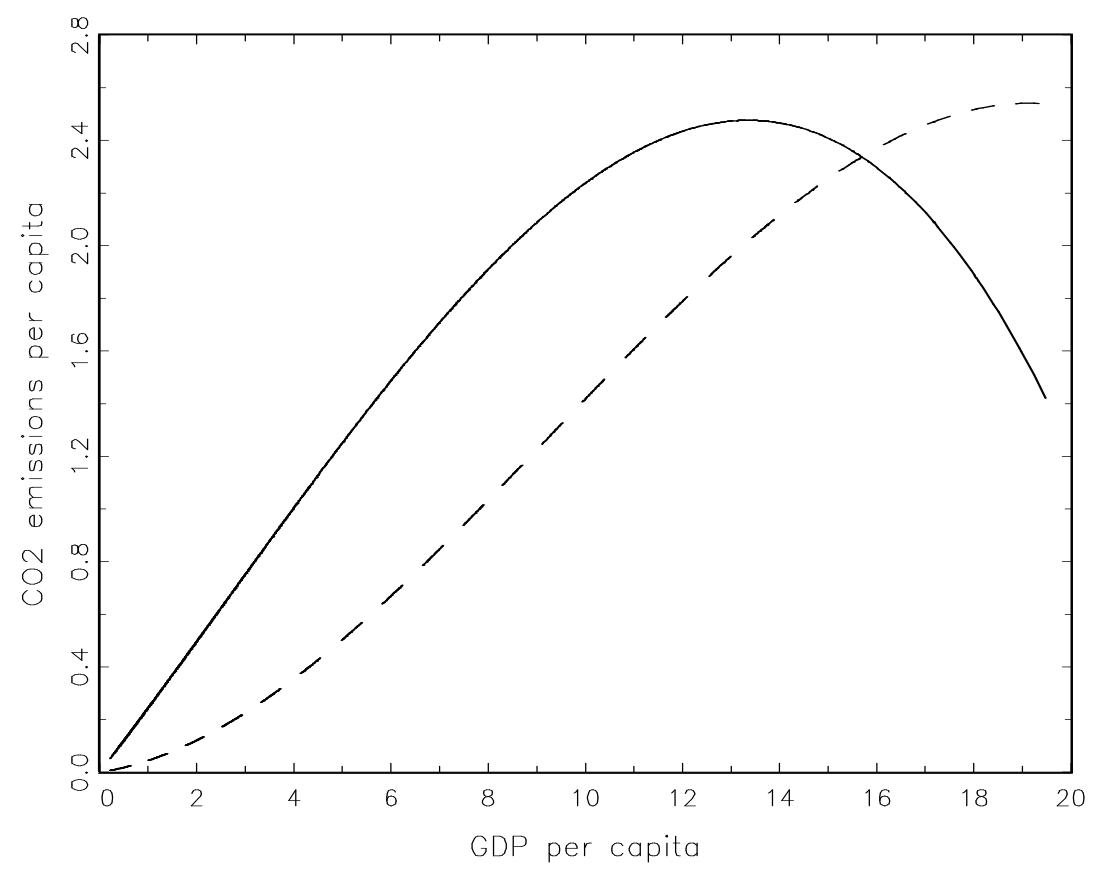

Figure 3: Parametric estimation of the relationship between $\mathrm{CO}_{2}$ emissions and GDP per capita. The solid and the dashed curves correspond to the within and the first-difference estimators, respectively. 